\title{
Evaluation of Infliximab Effects on Gastrointestinal Bleeding in Crohn's Disease Using Double-Balloon Endoscopy
}

\author{
Manzurul Chowdhurya, c Norihiko Kudara ${ }^{a}$ Toshimi Chiba ${ }^{a}$ \\ Masaki Endo ${ }^{a}$ Risaburo Akasaka ${ }^{a}$ Kazumitsu Tomita ${ }^{a}$ \\ Saori Fujiwara ${ }^{a}$ Tomomi Mizutani $^{a}$ Tamotsu Sugai ${ }^{b}$ \\ Yasuhiro Takikawa ${ }^{\mathrm{a}}$ Kazuyuki Suzuki ${ }^{\mathrm{a}}$ \\ aDepartment of Gastroenterology and Hepatology and ${ }^{\mathrm{b}}$ Division of Molecular \\ Diagnostic Pathology, Department of Pathology, Iwate Medical University, \\ Morioka, Japan; 'Ministry of Health and Family Welfare, Government of \\ Bangladesh, Dhaka, Bangladesh
}

\section{Key Words}

Crohn's disease · Infliximab · Double-balloon endoscopy · Gastrointestinal bleeding

\begin{abstract}
Tumor necrosis factor a plays an important role in the pathogenesis of Crohn's disease (CD). The effects of infliximab on gastrointestinal bleeding in CD have not yet been fully evaluated. Herein we describe three $C D$ cases who presented with gastrointestinal bleeding and received infliximab treatment. In case 1, double-balloon endoscopy showed a large ulcer with several irregularly shaped ulcers in the terminal ileum; 8 weeks after infliximab administration, complete healing of all lesions was observed. In case 2, double-balloon endoscopy showed linear ulcers and mucosal edema in the jejunum and ileum; 5 weeks after infliximab administration, all lesions were decreased in size and were healed. In case 3, double-balloon endoscopy revealed ulcerations and stenosis in the terminal ileum; 12 weeks after infliximab administration, ulcer healing and an increased diameter of the ileal stenosis were observed. These three cases have been receiving ongoing infliximab maintenance therapy and are currently symptom-free. Infliximab thus appears to be useful for treatment of gastrointestinal bleeding in CD patients.
\end{abstract}




\section{Introduction}

Crohn's disease (CD) is a chronic inflammatory disorder of the gastrointestinal tract. Although mild disease can be treated with 5-aminosalicylates (5-ASAs), many patients eventually require corticosteroids for symptom control [1]. Tumor necrosis factor $\alpha$ (TNF- $\alpha$ ) is a proinflammatory cytokine that plays an important role in CD pathogenesis [2-4]. Infliximab, a chimeric monoclonal antibody directed against TNF- $\alpha$ that neutralizes its biological activity [5], was the first biological therapy to be approved for $\mathrm{CD}$ and has become an important tool in the treatment of this disease.

Infliximab has been recommended by different organizations for induction therapy and maintenance therapy of $\mathrm{CD}$. The definitive indications for induction therapy with infliximab are: (1) moderate to severe inflammatory $C D$ with an inadequate response to conventional therapy (defined by severity of symptoms and/or lack of response to standard therapy such as corticosteroids, azathioprine, 6-mercaptopurine, and methotrexate); (2) fistulizing CD with draining cutaneous or perianal fistulas.

The definitive indications for maintenance therapy with infliximab are: (1) inflammatory or fistulizing CD that responded to initial induction therapy with infliximab and failed maintenance therapy with one or more immunosuppressive agents; (2) corticosteroid-treated CD that failed an attempt at corticosteroid sparing with one or more immunosuppressive agents [6]. Other potential uses of infliximab in different CD settings are currently under investigation. We have used infliximab in CD patients previously controlled by immunosuppressive agents who presented with perirectal bleeding. Herein we report the effects of infliximab on gastrointestinal bleeding in CD. This is the first report of evaluation of small bowel CD lesions before and after administration of infliximab using double-balloon endoscopy.

\section{Case Reports}

Case 1 was an 18-year-old male who was admitted to our hospital after complaining of melena for 1 day. He had a 2-year history of CD. His serum C-reactive protein (CRP) level was $2.7 \mathrm{mg}$. Colonoscopy showed a linear ulcer in the descending colon with no evidence of bleeding. A few aphthous ulcers were observed in the transverse colon and terminal ileum with no signs of bleeding. Double-balloon endoscopy revealed one large ulcer and several irregularly shaped ulcers in the terminal ileum (fig. 1a). The patient was given a single intravenous $5 \mathrm{mg} / \mathrm{kg}$ dose of infliximab. Eight weeks after infliximab administration, double-balloon endoscopy revealed a reduction in size and complete healing of the lesions (fig. 1b). The patient has been receiving infliximab maintenance therapy at a dose of $5 \mathrm{mg} / \mathrm{kg}$ every 8 weeks. He is currently symptom-free with no evidence of disease relapse.

Case 2 was a 21-year-old female who was admitted to our hospital after complaining of melena for 2 days. She had a 5-year history of CD. Her serum CRP level was $4.6 \mathrm{mg} / \mathrm{dl}$. Double-balloon endoscopy showed linear ulcers in the jejunum with ulcer scars. The ileum also showed ulcer scars with mucosal edema. The patient was given intravenous infliximab $5 \mathrm{mg} / \mathrm{kg}$. Five weeks after infliximab administration, double-balloon endoscopy showed that all lesions were decreased in size and were healed. The patient has been receiving infliximab maintenance therapy every 8 weeks. She is currently symptom-free.

Case 3 was a 31-year-old female who visited our hospital with mild abdominal pain without melena. On physical examination she was found to be anemic (hemoglobin level $5.9 \mathrm{~g} / \mathrm{dl}$ ) and her serum CRP was $1.0 \mathrm{mg} / \mathrm{dl}$. The patient had a 2-year history of CD. Colonoscopy showed aphthous ulcers in the colon. Subsequently, double-balloon endoscopy revealed ulcerations and stenosis in the terminal ileum (fig. 2a). The patient was given infliximab $5 \mathrm{mg} / \mathrm{kg}$. Twelve weeks after infliximab administration, double-balloon endoscopy showed ulcer healing and an increased diameter of the ileal stenosis (fig. 2b). The patient has been receiving infliximab maintenance therapy. She is currently symptom-free and her anemia is improving. 


\begin{tabular}{r|l|l|l} 
Case Reports $h$ Ch & $\begin{array}{l}\text { Case Rep Gastroenterol 2009;3:193-197 } \\
\text { Dol: } 10.1159 / 000224712\end{array}$ & Published online: July 31, 2009 & $\begin{array}{l}\text { I 2009 S. Karger AG, Basel } \\
\text { ISSN 1662-0631 } \\
\text { www.karger.com/crg }\end{array}$ \\
& & & \\
\hline
\end{tabular}

\section{Discussion}

Acute lower gastrointestinal hemorrhage in an unusual complication of CD that occurs in $0.9-6 \%$ of cases [7-9]. Localization of the disease site remains a major challenge.

Double-balloon endoscopy has been useful for identifying the bleeding site and also for excluding non-CD-related perirectal bleeding. Both medical and surgical modalities are used to manage lower gastrointestinal bleeding due to CD. Traditionally, medical treatment of CD primarily consisted of 5-ASAs and corticosteroids, with other, nonsurgical therapies including endoscopic treatment and interventional angiography. However, the outcomes or these therapies are not satisfactory, and $60-91 \%$ of cases require surgery [8]. Furthermore, up to $35 \%$ of medically treated patients experience recurrent bleeding episodes [7]. Although rebleeding is negligible in patients who undergo primary excisional surgery, such surgery is associated with various hazardous complications.

The anti-TNF- $\alpha$ antibody infliximab has been shown to induce rapid mucosal healing $[10,11]$. Infliximab treatment of severe, recurrent CD presenting as massive lower gastrointestinal bleeding has been shown to result in rapid mucosal healing and to prevent recurrent bleeding $[12,13]$, suggesting that infliximab may offer a viable treatment alternative to surgery for patients with acute massive or chronic refractory bleeding [14]. Furthermore, infliximab could potentially modify the expected time course of the disease in a relevant number of patients by stopping further development of, or causing regression of, stenotic lesions, thereby postponing or avoiding surgical interventions [15]. In our series, all three patients promptly responded to infliximab therapy, as their gastrointestinal bleeding stopped after a single dose and stenosis also improved. Furthermore, these patients have also received continual maintenance therapy with no evidence of disease relapse. It therefore seems feasible that infliximab may be useful in treating $\mathrm{CD}$ relapse characterized by gastrointestinal bleeding in patients who previously received other therapies.

In conclusion, we have reported that all of our patients promptly responded to infliximab therapy, manifested as halting of gastrointestinal bleeding. This is the first report to show double-balloon endoscopic findings before and after administration of infliximab, which appears to be useful for stopping gastrointestinal bleeding and thereby preventing the need for surgery in CD patients. 


\begin{tabular}{r|l|l|l} 
Case Reports $/ \mathrm{h}$ & $\begin{array}{l}\text { Case Rep Gastroenterol 2009;3:193-197 } \\
\text { D0I: 10.1159/000224712 }\end{array}$ & Published online: July 31, 2009 & $\begin{array}{l}\text { @ 2009 S. Karger AG, Basel } \\
\text { ISSN 1662-0631 } \\
\text { www.karger.com/crg }\end{array}$ \\
\hline
\end{tabular}

Fig. 1. a Double-balloon endoscopy showed a large ulcer and several irregularly shaped ulcers in the terminal ileum. b Double-balloon endoscopy showed a reduction in size and complete healing of the lesions in the terminal ileum 8 weeks after infliximab treatment.

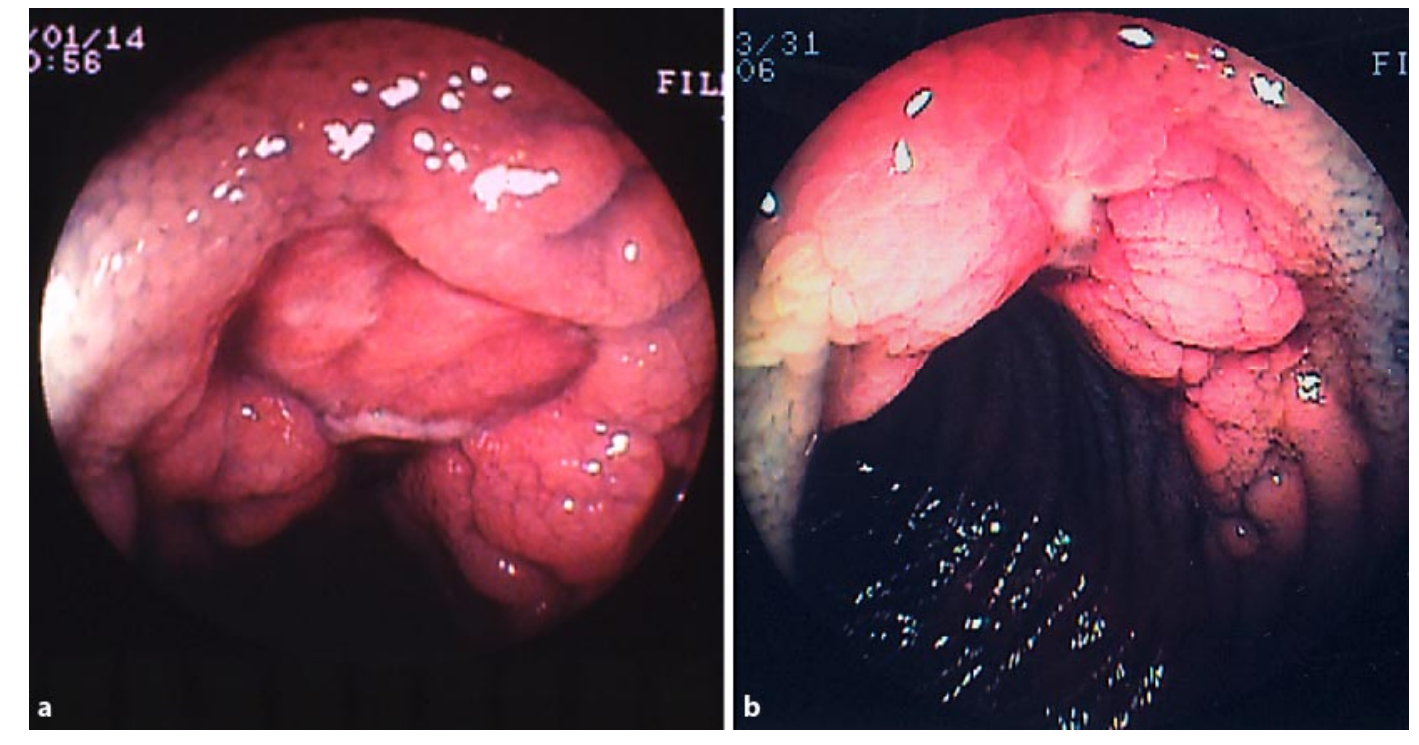

Fig. 2. a Double-balloon endoscopy revealed ulcerations and stenosis in the terminal ileum.

b Double-balloon endoscopy showed ulcer healing and an increased diameter of the ileal stenosis 12 weeks after infliximab treatment.

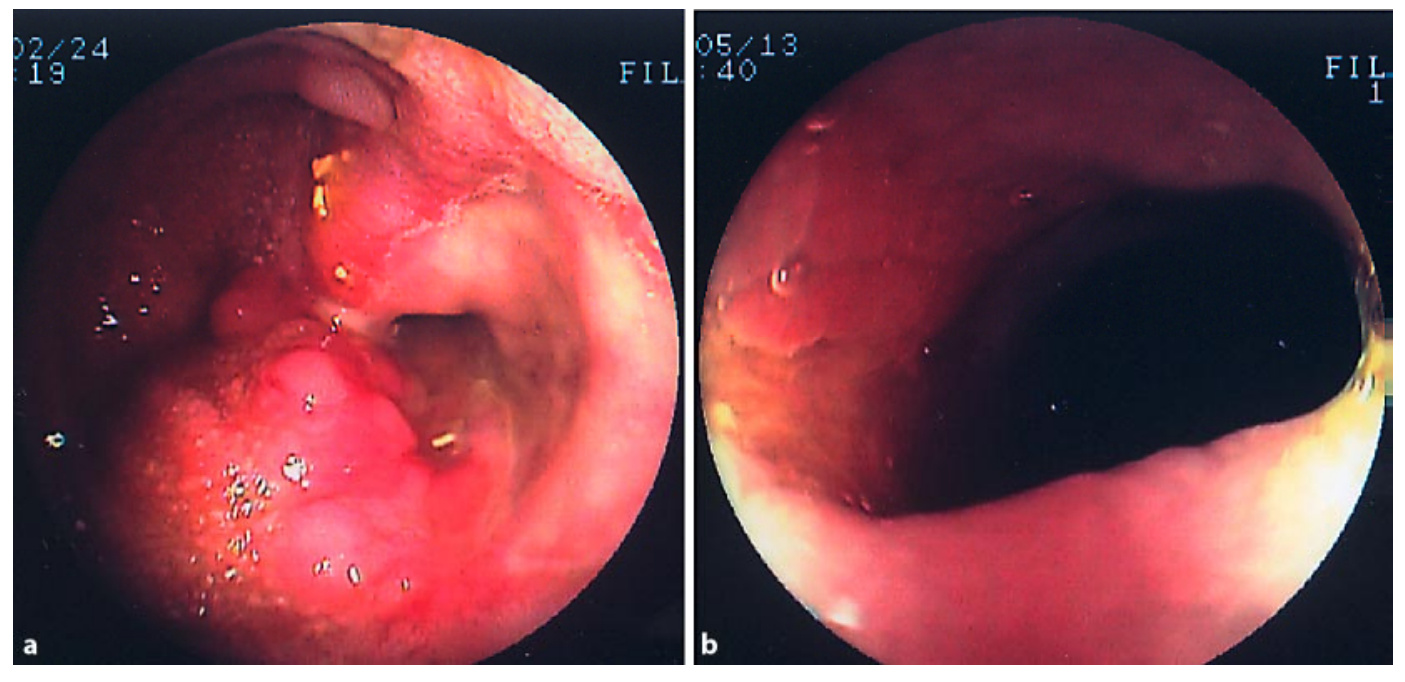




\section{References}

1 Faubion WA Jr, Loftus EV Jr, Harmsen WS, et al: The natural history of corticosteroid therapy for inflammatory bowel disease: a population-based study. Gastroenterology 2001;121:255-260.

-2 Breese EJ, Michie CA, Nicholls SW, et al: Tumor necrosis factor alpha-producing cells in the intestinal mucosa of children with inflammatory bowel disease. Gastroenterology 1994;106:1455-1466.

3 MacDonald TT, Hutchings P, Choy MY, et al: Tumour necrosis factor-alpha and interferon-gamma production measured at the single cell level in normal and inflamed human intestine. Clin Exp Immunol 1990;81:301-305.

-4 Schreiber S, Nikolaus S, Hampe J, et al: Tumour necrosis factor alpha and interleukin 1beta in relapse of Crohn's disease. Lancet 1999;353:459-461.

5 Knight DM, Trinh H, Le J, et al: Construction and initial characterization of a mouse-human chimeric anti-TNF antibody. Mol Immunol 1993;30:1443-1453.

-6 Sandborn WJ, Hanauer SB: Infliximab in the treatment of Crohn's disease: a user's guide for clinicians. Am J Gastroenterol 2002;97:2962-2972.

7 Robert JR, Sachar DB, Greenstein AJ: Severe gastrointestinal hemorrhage in Crohn's disease. Ann Surg 1991;213:207-211.

-8 Cirocco WC, Reilly JC, Rusin LC: Life-threatening hemorrhage and exsanguination from Crohn's disease. Report of four cases. Dis Colon Rectum 1995;38:85-95.

-9 Driver CP, Anderson DN, Keenan RA: Massive intestinal bleeding in association with Crohn's disease. J R Coll Surg Edinb 1996;41:152-154.

10 D'haens G, Van Deventer S, Van Hogezand R, et al: Endoscopic and histological healing with infliximab anti-tumor necrosis factor antibodies in Crohn's disease: A European multicenter trial. Gastroenterology 1999;116:1029-1034.

11 van Dullemen HM, van Deventer SJ, Hommes DW, et al: Treatment of Crohn's disease with anti-tumor necrosis factor chimeric monoclonal antibody (cA2). Gastroenterology 1995;109:129-135.

12 Papi C, Gili L, Tarquini M, et al: Infliximab for severe recurrent Crohn's disease presenting with massive gastrointestinal hemorrhage. J Clin Gastroenterol 2003;36:238-241.

13 Tsujikawa T, Nezu R, Andoh A, et al: Infliximab as a possible treatment for the hemorrhagic type of Crohn's disease. J Gastroenterol 2004;39:284-287.

14 Belaiche J, Louis E: Severe lower gastrointestinal bleeding in Crohn's disease: successful control with infliximab. Am J Gastroenterol 2002;97:3210-3211.

15 Pallotta N, Barberani F, Hassan NA, et al: Effect of infliximab on small bowel stenosis in patients with Crohn's disease. World J Gastroenterol 2008;14:18851890. 